\title{
Elites y conflictividad en el seno de las aljamas mudéjares castellanas a fines de la Edad Media: exención tributaria y redes clientelares*
}

\author{
Pablo Ortego Rico \\ Universidad Complutense de Madrid
}

RESUMEN: Estudio de los conflictos desarrollados en las aljamas mudéjares castellanas durante el siglo $X V$, con especial énfasis en el análisis de las disputas asociadas a la presencia de grupos privilegiados integrados en redes clientelares que trascendian el marco de la comunidad musulmana local. Para este propósito hemos considerado dos casos de estudio representativos. Por un lado, el análisis del conflicto sostenido entre la aljama de Trujillo y la familia Plaza permite profundizar en el conocimiento de las formas de exclusión desarrolladas por la comunidad musulmana contra grupos privilegiados integrados en facciones urbanas. Por otro, se han estudiado las disputas desarrolladas en el seno de la comunidad mudéjar de Guadalajara entre los miembros privilegiados de la clientela del linaje Mendoza y la aljama, y su relación con los conflictos entre facciones mudéjares sostenidos a fines del siglo $\mathrm{XV}$.

* Siglas y abreviaturas empleadas: Archivo General de Simancas (AGS); Archivo Municipal de Guadalajara (AMG); Archivo de la Real Chancillería de Valladolid (ARCV); Cámara de Castilla (CCA); Contaduría Mayor de Cuentas, Primera Época (CMC, $1^{a}$ ép.); Mercedes y Privilegios (MyP); Real Academia de la Historia (RAH); Registro General del Sello (RGS); maravedíes (mrs); Sección Nobleza Archivo Histórico Nacional (SNAHN). Este trabajo forma parte de los resultados de la Acción Integrada «Facciones, linajes y conflictos en la Europa bajomedieval. Modelos y análisis a partir de las ciudades españolas e italianas», financiada por el Ministerio de Ciencia e Innovación (Programa Nacional de Internacionalización de la I+D, Subprograma de Proyectos Internacionales) (IT2009-0052), y de los siguientes Proyectos de Investigación financiados por el Programa Estatal de Fomento de la Investigación Científica y Técnica de Excelencia, Subprograma Estatal de Generación de Conocimiento, del Ministerio de Economía y Competitividad: «El negocio de la fiscalidad: gestión tributaria, redes financieras y grupos de poder en la Corona de Castilla (1450-1550)» (HAR2013-45788-C4-1P) y «Prácticas de comunicación y negociación en las relaciones de consenso y pacto de la cultura política castellana. Ca. 1230-1504» (HAR2013-42211-P). 


\title{
PALABRAS CLAVE: mudéjares; aljamas; fiscalidad; exenciones; Casti- lla; siglo XV.
}

Elites and disputes in the Castilian Mudejar aljamas at the end of the Middle Age: fiscal exemption and client-networks.

\begin{abstract}
Study of the conflicts developed in the Castilian Mudejar aljamas during the Fifteenth Century, whit special emphasis on the analysis of the disputes associated to the presence of privileged groups integrated in clientnetworks which transcended the framework of the local Muslim community. For this purpose we have considered two representative cases of study. On the one hand, the analysis of the dispute held between the Trujillo aljama and the Plaza family allows us to deepen our knowledge of the exclusion forms founded by the Islamic community against privileged groups integrated in urban factions. On the other, we have studied the disputes developed within the Mudejar community of Guadalajara between the privileged members of the Mendoza lineage clientele and the aljama, and its connection whit the conflicts held between Mudejar factions at the end of the Fifteenth century.
\end{abstract}

KEY WORDS: Mudejars; aljamas; taxation; privileges of exemption; Castile; Fifteenth century.

\section{INTRODUCCIÓN}

El estudio de las relaciones políticas articuladas en el seno de las comunidades mudéjares castellanas ha experimentado una profunda renovación en los últimos años gracias a los trabajos dedicados por autores como J.-P. Molénat o A. Echevarría Arsuaga al análisis de las formas de representación política de la minoría musulmana y al ejercicio del poder jurisdiccional en el marco de las aljamas ${ }^{1}$. En este sentido, si algo demuestran estos estudios es lo complejo que resulta determinar el origen de los fenómenos de elitización observados y su relación con factores endógenos y/o exógenos a la dinámica en la cual se desarrollaba la vida de estas comunidades. Entre los primeros, qué duda cabe que la capacidad de liderazgo asociada al prestigio religioso y a la formación cultural pudo desempeñar un papel relevante, máxime si consideramos la necesidad que tenían unos grupos tan reducidos y aparentemente aislados de contar con elites que contribuyesen a mantener viva la llama del Islam en un contexto mayoritariamente cristiano. En este sentido, el problema nos lleva a plantear si realmente existió una identificación de lo que podríamos denominar las elites o «jerarquías naturales» nacidas de procesos internos desarrollados en el seno de cada comunidad religiosa, con las oligarquías políticas del

1 MOLÉNAT: 2001: 45-53; 2003b: 563-577. ECHEVARRÍA ARSUAGA, 14 (Madrid, 2001): 93-112. 
grupo propiamente dichas, así consideradas en función del desempeño de cargos y oficios, tanto en el marco de la aljama como a nivel general, dotados de poder de decisión en materia judicial e impositiva - alcaldía mayor de las aljamas de moros de Castilla, alcaldías mayores locales, oficio de repartidor de las aljamas de moros - y reconocidos y legitimados por el poder cristiano como consecuencia, en no pocos casos, del establecimiento de relaciones informales o la prestación de servicios especializados ${ }^{2}$.

De esta forma, es precisamente en el análisis de los marcos de relación que abrían cauces de participación política a algunos miembros de la minoría donde entra en juego la valoración del elemento exógeno en el ascenso logrado por determinados individuos y linajes a partir de los vínculos de patrocinio sostenidos con los poderes cristianos (Corona, nobleza, concejos) o con aquellos mudéjares que, respaldados por la Monarquía u otros poderes, habían alcanzado previamente responsabilidades político-jurídicas al más alto nivel. Con ello, la aparente uniformidad del grupo ligada a la definición de sus límites y fronteras culturales a partir del elemento religioso da paso a una visión del mismo mucho más rica en matices, en la cual tienen cabida fenómenos como la emergencia de grupos privilegiados, o la aparición de conflictos políticos internos asociados a la formación de redes de poder y estructuras de agregación muy similares, aunque a una escala mucho más reducida, a los bandos presentes a fines del Medievo en la mayor parte de los concejos castellanos $^{3}$, cuyo desarrollo se vio determinado en algunos casos por la propia instrumentalización de los lazos sostenidos con los poderes cristianos realizada por aquellos mudéjares que deseaban alcanzar, mantener o ratificar un determinado estatus. Ello supone abandonar el análisis de la dinámica en la cual se movieron las comunidades mudéjares castellanas únicamente a partir de aquellos elementos que remarcan la supeditación del grupo al poder cristiano, o su caracterización como minoría marginal ${ }^{4}$, para pasar a entender estas relaciones en unos términos de reciprocidad, aunque esta se manifestara de forma asimétrica en virtud de la diferente consideración de los beneficios que implicaba para cada parte el mantenimiento del nexo establecido.

En este sentido, la presencia en algunas comunidades de mudéjares exentos de tributación, fenómeno ya estudiado para los casos de Aragón y Portugal $^{5}$, es uno de los elementos que, junto al desempeño de oficios y cargos dotados de contenido jurisdiccional o fiscal, permite ahondar en los fenómenos

2 Sobre estos cargos ver TORRES FONTES, 32 (Madrid, 1962): 131-182. ECHEVARRÍA ARSUAGA, 14/1 (Madrid, 2003): 139-168. MOLÉNAT, 1999: 175-184. ORTEGO RICO, en prensa.

3 LADERO QUESADA, 1991: 105-134.

4 ECHEVARRÍA ARSUAGA, 18 (Madrid, 2008): 50-54.

5 CATLOS, 2004: 329-356; 2008: 133-182. FERRER I MALLOL, 2007: 341-352. LOPES DE BARROS, 2008: 101-132. 
de elitización y diferenciación social así, como en la génesis de conflictos internos motivados no solo por el desequilibrio en los repartos tributarios llevados a cabo en el marco de la aljama que esta situación producía, sino también por la tensión que la concesión de estas franquezas generaba al romper los marcos de solidaridad comunitarios establecidos a partir del vínculo religioso compartido. No obstante, a pesar de esa potencialidad, en el caso castellano apenas se ha prestado todavía atención al estudio contextualizado de la exención mudéjar y sus implicaciones políticas y sociales, de forma que, como primera aproximación al fenómeno, abordaremos el estudio de dos casos representativos relativos a las aljamas de Trujillo y Guadalajara, que permiten observar su complejidad y su conexión con el sostenimiento de relaciones exógenas que evidencian la fractura interna experimentada en muchas comunidades musulmanas a fines del Medievo.

\section{Los conflictos entre la aljama de Trujillo y el linaje Plaza: eX- CLUSIÓN COMUNITARIA Y PRIVILEGIO}

E1 25 de junio de 1479 la reina Isabel se dirigía desde Trujillo a la aljama musulmana de la misma ciudad, y a los recaudadores, empadronadores y cogedores de los pechos y tributos pagados por los moros a ella adscritos, como consecuencia de la denuncia presentada por su convecino, el musulmán Hamete o Hamed. El motivo de la queja no era otro que el incumplimiento por parte de las autoridades de la aljama del privilegio de exención fiscal que Juan II había otorgado a su padre Mahomad de la Plaza y a sus descendientes, toda vez que tanto el propio Hamed como sus hermanos habían sido incluidos recientemente en los padrones confeccionados para el pago de los tributos directos que debía aportar la comunidad mudéjar, y recibían «fatigas» y apremios por parte de sus correligionarios ${ }^{6}$. Se trataba, pues, de una súplica relacionada con un conflicto interno que atañía a uno de los principales elementos a través de los cuales el poder cristiano construía la identidad de la minoría mudéjar, planteada a todas luces aprovechando la presencia de la reina en Trujillo durante el verano de 1479. De forma paralela, la aljama formulaba por las mismas fechas una demanda ante el poder real, relacionada con el cumplimiento de la exención de huéspedes que disfrutaba la mezquita situada en el arrabal urbano — ratificada el 5 de julio de 1479, y de nuevo el 23 de agosto del mismo año-, según parece ocupada e maltratada por ciertos hombres, mujeres y bestias vinculados al séquito regio 7 .

6 AGS, RGS, junio de 1479, f. 13.

7 AGS, RGS, julio de 1479, f. 23. Ed. LADERO QUESADA, 1989: 105-106. Sobrecarta de la merced, AGS, RGS, agosto de 1479, f. 29. 
Aunque en ambos casos la Corona respondía de forma favorable a unos requerimientos que incidían en el necesario reconocimiento de privilegios disfrutados previamente, los efectos de ambas exenciones para la aljama no podían resultar más divergentes: mientras la franqueza de huéspedes reconocida a la mezquita implicaba un beneficio para toda la comunidad de creyentes traducido en una disponibilidad completa del espacio dedicado a la atención del culto religioso y de todos sus recursos, la ratificación de la exención tributaria disfrutada por la familia Plaza contribuía a romper la unidad del grupo al perpetuar unas distinciones y jerarquías sancionadas por el privilegio lesivas a los intereses comunitarios por los cuales, teóricamente, velaba la aljama. De ahí, el elevado grado de conflictividad relacionado con el cumplimiento de esta exención observado hasta la conversión de la minoría mudéjar en 1502.

A pesar de la ausencia de estudios monográficos, a fines de la Edad Media la de Trujillo era - junto con la de Plasencia - una de las comunidades mudéjares de realengo más populosas de la actual Extremadura, región donde la historiografía ha resaltado tradicionalmente la importancia de las aljamas adscritas a los territorios jurisdiccionales de las órdenes militares de Alcántara y Santiago $^{8}$. A tenor de los datos fiscales conservados, en 1430 la aljama trujillana contribuía en concepto de cabeza de pecho con $1.400 \mathrm{mrs}$ de la moneda vieja, cifra poco ilustrativa que responde a la fosilización experimentada por el tributo a lo largo de la segunda mitad del siglo XIV ${ }^{9}$. Por su parte, en la evolución de las cifras correspondientes al servicio y medio servicio repartido durante la segunda mitad del siglo XV se observa un crecimiento desde los $3.500 \mathrm{mrs}$ distribuidos en 1463 hasta los $6.500 \mathrm{mrs}$ pagados en 1501, aunque desde 1491 en dicha cantidad también se incluía a los escasos moros residentes en la vecina ciudad de Cáceres ${ }^{10}$. Por lo tanto, todo apunta a que la comunidad mudéjar de Trujillo experimentó cierta revitalización demográfica en las últimas décadas del siglo XV, como por otra parte parece ratificar el incremento en el número de pechas aportado por la aljama en el llamado servicio de los castellanos de oro establecido en 1482, que pasó de 71 en 1495 a 91 en 1501, alcanzando en 1498 su punto máximo: $100^{11}$. No obstante, la escasez de documentos apenas permite profundizar en los aspectos organizativos de la comunidad, que al parecer se vio afectada por una pérdida de la au-

8 LADERO QUESADA, 1989: 32-33.

9 LADERO QUESADA, 27 (Palma de Mallorca, 2001): 21.

10 LADERO QUESADA, 1989a: 92. VIÑUALES FERREIRO, 14/1 (Madrid, 2003): 190. En 1496 se repartió la cantidad máxima: $7.450 \mathrm{mrs}$.

11 LADERO QUESADA, 8 (Barcelona, 1972-1973): 489. 
tonomía judicial ejercida por los alcaldes moros locales ${ }^{12}$, similar a la observada en otras aljamas como las de Ágreda o Segovia ${ }^{13}$.

En este contexto de penuria documental, resulta altamente significativo que la mayor parte de las fuentes relativas a la comunidad mudéjar de Trujillo conocidas se refiera casi de forma exclusiva al contencioso desarrollado desde mediados del siglo XV entre la aljama y los miembros de la familia Plaza, presionados de forma recurrente por sus correligionarios para que renunciasen a sus privilegios fiscales, siguiendo una dinámica muy similar a la observada por M.T. Ferrer i Mallol en la aljama zaragozana durante los siglos XIII-XIV, que permite profundizar en el análisis de fenómenos de exclusión asociados a la conceptualización de determinados individuos como un «cuerpo extraño» a la comunidad religiosa de adscripción en virtud del reconocimiento de un estatus diferenciado por parte de la autoridad cristiana ${ }^{14}$.

Tal y como adelantamos, la franqueza tributaria disfrutada por la familia Plaza tiene su origen durante el reinado de Juan II. El 4 de agosto de 1432 el rey concedía a Mahomad de Trujillo - identificado en otros documentos con Mahomad de la Plaza-, hijo de don Hamed, y a su mujer, hijos y descendientes, una generosa exención fiscal que les dispensaba del pago de todos los tributos, pechos, empréstitos y derechos reales o concejiles abonados por los mudéjares trujillanos o los de cualquier otra comunidad del Reino. Asimismo, la merced incluía una mención expresa a la posible oposición mostrada por parte de las autoridades religiosas musulmanas - representadas por los alfaquíes-, síntoma inequívoco de que la Corona era plenamente consciente de la problemática que podía suscitar la presencia de estos grupos privilegiados en el seno de sus respectivas comunidades de adscripción ${ }^{15}$. Por otro lado, aunque la concesión original omite las razones que llevaron al rey a otorgar el privilegio, ocultándolas bajo la fórmula genérica empleada habitualmente en estos casos — por los buenos e leales serviçios que me vos avedes fecho e fazedes de cada día-, se ha podido determinar su relación con los vínculos sostenidos por don Mahomad más allá del ámbito de su comunidad religiosa. Así, en la denuncia presentada por la aljama de Trujillo ante el Consejo Real antes de julio de 1484 que daba inicio a una nueva ofensiva destinada a limitar el alcance del privilegio se señala expresamente cómo «en vida del maestre de Calatrava [sic] don Gutyerre de Sotomayor e a su suplicaçión» Juan II había otorgado a Mahomad de la Plaza la controvertida exención ${ }^{16}$. Más allá

12 Ver a este respecto AGS, RGS, mayo de 1476, f. 346.

13 ABBOUD-HAGGAR, 6 (Madrid, 1999): 415-432. ECHEVARRÍA ARSUAGA, 14 (Madrid, 2001): 99-102.

14 FERRER I MALLOL, 2007: 341-352.

15 Carta de privilegio (1432, agosto 4. Salamanca) inserta en AGS, MyP, leg. 94, f. 54.

16 AGS, RGS, julio de 1484, f. 26. 
del error del escribano, que identifica a Gutierre de Sotomayor (1400-1453) como maestre de Calatrava cuando realmente lo había sido de la orden de Alcántara, resulta interesante constatar la coincidencia existente entre la fecha de la merced otorgada al mudéjar y la del acceso de don Gutierre a la dignidad maestral como consecuencia de su intervención en favor de Juan II en el contexto de las disputas sostenidas entre el partido lunista y los infantes de Aragón desde 142917. En este sentido, todo apunta a que en aquel momento Mahomad de la Plaza formaba parte de la clientela del nuevo maestre, que probablemente aprovechó su renovada posición en la corte para obtener del rey una gratificación para el mudéjar por los servicios prestados ${ }^{18}$. Sea como fuere, lo cierto es que, como en otros casos, fueron los vínculos entablados con los poderes cristianos, y no la posición socio-política, el prestigio, o el papel desempeñado en el seno de la comunidad religiosa, los que determinaron el acceso de la familia Plaza al privilegio fiscal, evidenciando el importante papel que la inserción en estructuras político-sociales verticales tenía asignado en los procesos de diferenciación social y jerarquización jurídica observados a fines de la Edad Media en las aljamas mudéjares castellanas.

Ya en 1447 tenemos constancia del estallido de un primer conflicto entre los Plaza y la comunidad mudéjar de Trujillo que marcará la senda por la cual discurrirían en el futuro sus relaciones. El 4 de diciembre de este año Juan II libraba una sobrecarta a petición de Mahomad de la Plaza motivada en la oposición mostrada por la aljama trujillana a aceptar la exención fiscal en lo que atañía al pago de los tributos propios de la minoría, a la sazón la cabeza de pecho y el servicio y medio servicio. Dicho incumplimiento, que se vio acompañado de fuertes presiones, era la respuesta articulada por la institución mudéjar ante la negativa de la Corona a aceptar, como forma de alivio económico, el descuento de la cantidad que correspondía abonar al grupo de exentos de la cuantía total que debía aportar la comunidad. No obstante, aunque la exención pudiera llevar asociado un leve incremento de la presión fiscal sobre los restantes correligionarios, generadora de cierto malestar, entendemos que este no era el problema fundamental, habida cuenta del limitado peso cuantitativo que tanto la cabeza de pecho como el servicio y medio servicio tenían asignado en el contexto fiscal de la época. En este sentido, es posible que la contumaz oposición manifestada a partir de este momento por la aljama a reconocer la exención de los Plaza se encontrase mucho más ligada a la ruptura de las solidaridades internas que el privilegio generaba, máxime si tenemos en cuenta la universalidad que el Islam establece en relación al pago de los impuestos canónicos —es decir, los estipulados por la sharia (fundamental-

17 ORTEGA ÁLVAREZ, 24 (Madrid, 2011): 239-251.

18 No obstante, Mahomad de la Plaza no aparece mencionado en la clientela del maestre de Alcántara estudiada por ORTEGA ÁLVAREZ, LXVI/1 (Badajoz, 2010): 239-286. 
mente la limosna, zakât o sadaqa) — para todos aquellos que cumpliesen una serie de condiciones ${ }^{19}$, principio que la práctica comunitaria pudo extender a la retribución de aquellos impuestos extra-canónicos con los que las autoridades gravaban específicamente a las aljamas musulmanas. En cualquier caso, en este momento la Corona trató de zanjar el conflicto generado mediante una solución de consenso que pasaba por la ratificación de Mahomad de la Plaza y sus hijos como beneficiarios de la franqueza, y la autorización de un descuento de $500 \mathrm{mrs}$ anuales en la cantidad total con que contribuía la aljama en los dos conceptos tributarios señalados ${ }^{20}$.

El compromiso alcanzado en 1447 contribuyó a relajar la tensión de forma transitoria, aunque no resolvía un problema que llegó a alcanzar una notable proyección tras la muerte de Mahomad de la Plaza. El 22 de noviembre de 1472 Enrique IV confirmaba a su hijo Hamed/Hamete la exención tributaria concedida cuarenta años atrás a su padre ${ }^{21}$. Es probable que, después del fallecimiento de Mahomad, surgiesen de nuevo voces en la aljama dispuestas a limitar el alcance del privilegio, o bien que la familia Plaza, temerosa de sufrir nuevas presiones buscase la ratificación de su estatus por parte de la Corona. Lo cierto es que de nuevo, el 20 de mayo de 1477, los Reyes Católicos confirmaban a Hamed de la Plaza su merced desde Trujillo22, en un momento marcado por el fin del asedio a la fortaleza urbana, que solo capitularía el 24 de junio a pesar de que la ciudad ya había alzado pendones por Isabel en abril de 1476. En este sentido, aunque carecemos de datos al respecto, todo apunta a que las circunstancias de conflictividad política vividas en Trujillo desde la muerte de Enrique IV favorecieron la reactivación del conflicto fiscal entre la aljama y Hamed de la Plaza, cuyos privilegios fueron ratificados en junio de 1479 , tal y como señalábamos al comienzo de la exposición ${ }^{23}$.

Ante la cascada de confirmaciones que legitimaban a los Plaza como beneficiarios de la franqueza tributaria, la aljama no tuvo más remedio que realizar un cambio de estrategia que pasaba por la judicialización del conflicto ante las autoridades cristianas, a las cuales se terminó reconociendo su capacidad para arbitrar en un problema interno de la comunidad. De este modo, el 5 de julio de 1484 los reyes comisionaban a Sancho del Águila, alcaide de la fortaleza de Trujillo, para que iniciase — a raíz de la denuncia planteada por la

19 Sobre el sistema impositivo islámico y su traducción a la etapa mudéjar ver ABBOUD-HAGGAR, 1997: 170-174; 31 (Madrid, 2008): 475-512.

20 Sobrecarta dada por Juan (1447, diciembre 4. Aranda de Duero) inserta en AGS, MyP, leg. 94, f. 54.

21 Sobrecarta de confirmación dada por Enrique IV (1477, mayo 20. Segovia) inserta en AGS, MyP, leg. 94, f. 54. 94, f. 54.

22 Sobrecarta de privilegio y confirmación (1477, mayo 20) inserta en AGS, MyP, leg.

23 AGS, RGS, junio de 1479, f. 13. 
aljama ante el Consejo Real - una pesquisa en relación a la exención disfrutada por el barbero Hamed, hijo de Mahomad de la Plaza, y sus familiares ${ }^{24}$. Según señalaba el memorial de agravios presentado, en aquel momento la familia Plaza, entre cuyos miembros se encontraban los más ricos e caudalosos de la dicha aljama - por lo tanto los que más debían contribuir, aplicando el criterio de distribución de la carga fiscal basado en el patrimonio, vigente en buena parte de las comunidades mudéjares castellanas ${ }^{25}$-, estaba formada por más de veinte individuos que en pocos años podrían llegar a ser más de çinquenta personas hermanos, e fijos, e nietos del dicho Mahomad de la Plaça que gozan e esperan gozar del dicho previllejo. Por ello, la aljama entendía que esta situación generaría en un corto espacio de tiempo un profundo desequilibrio entre el número de moros pecheros, cada vez más reducido, $\mathrm{y}$ el grupo de exentos adscritos al lynaje del dicho Mahomad de la Plaça, cada vez más numeroso, susceptible de provocar sy non les ayudasen a contribuyr e pagar en los pechos e derechos e serviçios la pérdida y destrucción de una comunidad calificada como pobre e pequeña ${ }^{26}$. Más allá del contraste interesado entre la riqueza de la familia Plaza y la pobreza de la aljama, el empleo del término linaje para referirse al grupo de exentos tampoco parece en absoluto inocente, habida cuenta de que la defensa de los privilegios asociados al vínculo familiar sostenido entre los Plaza se manifestaba en esas circunstancias como antagónica al vínculo religioso compartido que marcaba el límite de las solidaridades internas del grupo defendidas con tanto fervor por parte de la aljama.

Por otro lado, valiéndose de un argumento que en absoluto respondía al contenido de la franqueza originaria - en la cual se reconocía explícitamente su carácter hereditario-, la aljama distinguía al difunto Mahomad de la Plaza como único beneficiario del privilegio de exención, lo cual situaba al margen de la legalidad el rechazo de sus descendientes a pagar todo un conjunto de contribuciones explicitadas en la denuncia. Algunas, como el servicio y medio servicio, apenas tenían importancia cuantitativa a fines del siglo $\mathrm{XV}$, aunque mantenían su valor simbólico como uno de los elementos que remarcaban la dependencia de la minoría mudéjar del poder cristiano; otras respondían a las neçesydades internas de la aljama; finalmente, las cargas más relevantes a nivel cuantitativo - contribución de la Hermandad, servicio de los castellanos de oro, empréstitos echados en l'ayuda de Portugal, la llyeba de Alhama-, eran un signo de la nueva época iniciada tras el acceso de Isabel y Fernando al trono. En este sentido, conviene tener presente el clima emocional que debió generar en muchas aljamas el fuerte incremento en la presión fiscal asociado al establecimiento de estos nuevos tributos, así como su impacto en la degrada-

24 AGS, RGS, julio de 1484, f. 26.

25 ORTEGO RICO, en prensa.

26 AGS, RGS, julio de 1484, f. 26. 
ción de las condiciones de vida de la minoría y en la aparición de conflictos internos ligados a los sistemas de reparto articulados, tendentes a favorecer la exención de las elites y grupos enriquecidos ${ }^{27}$.

Por último, la denuncia planteada aporta un nuevo dato que permite profundizar, por un lado, en los vínculos exógenos sostenidos por la familia Plaza, y por otro, en la convulsa situación interna que vivía la comunidad mudéjar de Trujillo a fines del siglo XV. Según indicaba la aljama en el escrito presentado ante el Consejo Real, el moro Hamed...

...en menospreçio de nuestra justiçia, con fabor de algunos caballeros de la dicha çibdad, diz que a sydo cabsa de rebolver algunos ruydos e alborotos con çiertos moros de la dicha aljama, de los quales diz que se han recresçido muertes e feridas de onbres e grandes costas e gastos a la dicha aljama ${ }^{28}$.

Con ello se explicitaba la inserción de la familia Plaza en estructuras urbanas de agregación vertical que trascendían el ámbito de la comunidad musulmana, delimitada a partir de un vínculo como el religioso de marcado carácter horizontal. De hecho, la participación de algunos miembros de la familia Plaza en las luchas banderizas que habían caracterizado el escenario político trujillano durante la contienda sucesoria castellana es un hecho constatado. Así lo demuestra la mención a Alharen [sic], moro fijo de Abdalla Chicato —este último identificado en un documento de 1502 como hijo de Yuçaf de la Plaza ${ }^{29}$ en el perdón general que los reyes otorgaban en julio de 1476 a los integrantes del bando-linaje de Altamirano que encabezaba Luis de Chaves por los crímenes, robos y violencias que había provocado en la ciudad su actuación en defensa de los derechos de Isabel I al trono ${ }^{30}$. De este modo, todo apunta a que los vínculos clientelares estrechados por Hamed de la Plaza con determinados elementos del stablishment cristiano incorporaron un nuevo elemento a tener en cuenta a la hora de analizar los conflictos desarrollados en el marco de la aljama, muchos de los cuales trascendieron el componente estrictamente fiscal, que quizás constituía únicamente la «punta del iceberg» de unas relaciones mucho más complejas. Especialmente, porque la inserción en un determinado bando, o los vínculos sostenidos con la nobleza media caballeresca que detentaba el poder en la ciudad, brindaba a estos mudéjares privilegiados la oportunidad de defenderse desde una posición de mayor fortaleza de los ataques lanzados por sus propios correligionarios. De hecho, la aljama era plenamente consciente de que la familia Plaza contaba con el respaldo de algunos de estos poderes locales

27 ORTEGO RICO, en prensa.

28 AGS, RGS, julio de 1484, f. 26.

29 AGS, MyP, leg. 94, f. 54.

30 AGS, RGS, julio de 1476, f. 799. Sobre los bandos de Trujillo ver FERNÁNDEZDAZA ALVEAR, 6 (Madrid, 1985): 419-432. 
pues, tal y como señalaba en 1484 en relación a la denuncia fiscal planteada, d'este agravio fasta aqui non han hosado quexar por themor de algunas personas de la dicha çibdad que les heran muy contraryas ${ }^{31}$.

La respuesta colectiva de los Plaza a estas acusaciones no se hizo esperar. En ella, Hamed de la Plaza, sus hermanos Ali Boto, Yuçaf y Çayde, y su hijo Mahomad, más allá de reafirmar la legitimidad del privilegio otorgado por Juan II a su padre Mahomad de la Plaza, señalaban la falta de correspondencia de la información aportada por la aljama con la situación real en que se encontraba la comunidad. Su argumento, que trataba de minimizar el impacto de la franqueza, partía de la confusión entre pecheros y habitantes, de modo que, frente a los veinte exentos beneficiarios del privilegio a la altura de 1484 declarados por la aljama, los Plaza únicamente reconocían como tales a cinco individuos, identificados con los cinco cabezas de familia descendientes de Mahomad de la Plaza personados en la causa ${ }^{32}$. Este planteamiento introduce un nuevo elemento en la discusión relativo a la pervivencia entre los mudéjares de una articulación familiar de carácter patrilineal - muy próxima, en términos efectivos, a la realidad observada en el caso de los linajes nobiliarios castellanos-, pues nada se señala en relación a la posible transmisión hereditaria del privilegio por parte de las mujeres de la familia. Lo mismo ratifica uno de los puntos de la pesquisa ordenada por los reyes a Sancho del Águila, que debía averiguar cuáles de los exentos de la aljama eran desçendientes de varones $e$ quales de henbras e cómo se a guardado fasta aqui el dicho previllejo, síntoma inequívoco de que el disfrute de la merced estaba condicionado a su transmisión hereditaria por vía masculina. Lamentablemente desconocemos el resultado de la investigación llevada a cabo por el alcaide de Trujillo, que también se refería a la cantidad en la cual se encontraba encabezada la cabeza de pecho de la aljama; el número de herederos, hijos, nietos y parientes de Mahomad de la Plaza excusados del pago de tributos; la cuantía que les cabría a pagar de su parte del dicho pecho; el número de moros casados de la aljama; y la forma en la cual se había cumplido el descuento de 500 mrs reconocido en 1447.

31 AGS, RGS, julio de 1484, f. 26.

32 AGS, RGS, julio de 1484, f. 26. 


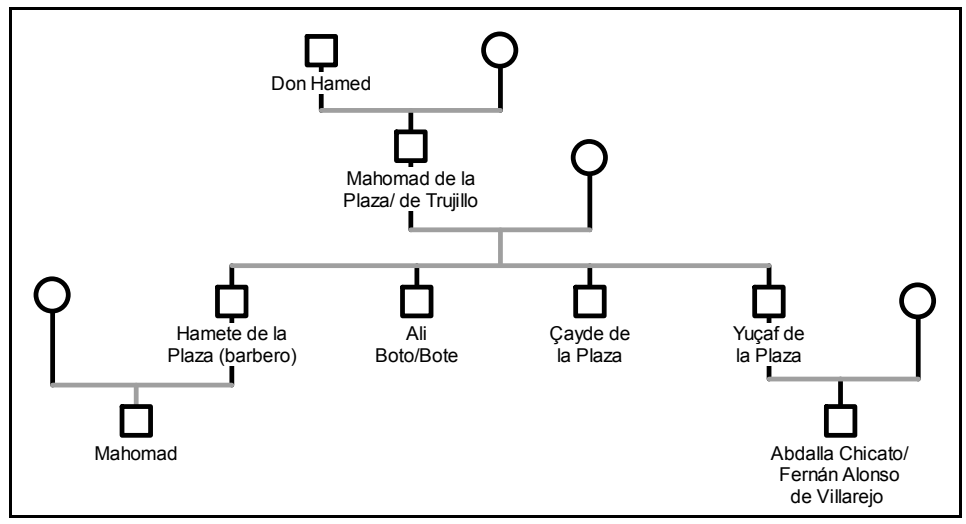

TABLA 1. Familia Plaza de Trujillo

Una vez finalizada la pesquisa, la aljama expresó de nuevo su descontento ante el Consejo Real por boca de sus procuradores Abrahem Cabeçudo y Abrahem Mazuelo, pues la averiguación llevada a cabo por Sancho del Águila se refería exclusivamente al pago de la cabeza de pecho, sin tener en cuenta los otros pechos e derramas que sobre la dicha aljama se reparten. En este sentido, los argumentos expuestos por la aljama antes del 5 de febrero de 1485 para subrayar el agravio del cual eran objeto los miembros de la comunidad mudéjar trujillana apenas diferían de los expresados anteriormente. Los representantes de la colectividad reiteraban el impacto negativo que el incremento de la presión fiscal tenía en la sobrecarga de los grupos más desfavorecidos - y por consiguiente en la disminución de los efectivos demográficos de la comunidad-, pues las neçesidades de la dicha aljama han creçido en grandes sumas de mrs, probablemente como consecuencia de la nueva política fiscal articulada por la Corona en relación a la minoría mudéjar desde el comienzo de la guerra de Granada. Igualmente se volvía a recalcar la descompensación entre el número de exentos herederos de Mahomad de la Plaza - que según su nuevo cálculo ascendía a 16 o 17 personas-, y los sesenta vecinos adscritos a la aljama. Llama poderosamente la atención la confusión que, quizás de forma intencionada, se establecía de nuevo entre las categorías «persona» y «vecino», cuyo tratamiento fiscal, como es de sobra conocido, era bien diferente. Con ello, probablemente la aljama trataba de exagerar la presión fiscal que soportaba la comunidad consecuencia, a su entender, de la notable fecundidad de la familia Plaza, pues del dicho Mahomad han quedado muchos fijos e nietos e bisnietos e desçendientes ${ }^{33}$.

33 AGS, RGS, febrero de 1485, f. 159. 
Aunque la apelación ante la Corona se convirtió en una de las vías de actuación preferentes de la aljama, habida cuenta de que era el único poder capacitado para revocar el privilegio de exención, otros miembros de la comunidad también iniciaron de forma paralela - bien a iniciativa particular, bien como parte de la estrategia conjunta emprendida por la aljama - acciones ante otros estamentos cristianos, como la justicia urbana de Trujillo ejercida por el corregidor. Ello expresaba, por un lado, la hostilidad y rechazo que mostraban hacia los Plaza parte de sus correligionarios, y por otro, la inoperancia de las estructuras judiciales propias encargadas en otras aljamas de sustanciar los pleitos civiles que afectaban exclusivamente a musulmanes. Por ejemplo, el 8 de abril de 1485 los reyes ordenaban la comparecencia ante el Consejo Real de Abrahem de Orellana y su hijo Abdalla Ismael, moros vecinos de Trujillo, a raíz de la denuncia presentada por Hamed de la Plaza, en nombre y como procurador de su hijo Abrahem de la Plaza, que había obtenido del lugarteniente del corregidor una sentencia desfavorable en cierto pleito - desconocemos si civil o criminal — que sostenía con los primeros ${ }^{34}$. En este sentido, más allá de la problemática fiscal, lo cierto es que a la altura del bienio 1484-1485 la comunidad musulmana trujillana vivía sometida a un elevado clima de tensión, manifestado en el desarrollo de diversos episodios violentos que no hacen sino evidenciar la ruptura de las solidaridades internas por la cual atravesaba. Por un lado, ya hemos visto cómo la aljama denunciaba antes de julio de 1484 la connivencia de la familia Plaza con algunos caballeros de la ciudad a la hora de mover ciertos ruydos e alborotos que habrían terminado con varios correligionarios muertos. Por otra parte, el 31 de agosto de 1484 los reyes ordenaban a la justicia urbana, a petición de Hamed de la Plaza, una investigación relativa a la muerte de su primo Abdalla Farax asesinado a manos de Mahomad Crespo y del zapatero Alí de Castilblanco ${ }^{35}$, estando él salvo e seguro en la zona del Resvaladero ${ }^{36}$. Todavía en diciembre de 1485 no se habían aplicado las penas en que habían incurrido sus ejecutores, tal y como denunciaban ante los reyes Hamed y su hermano Yuçaf de la Plaza, que además subrayaban la premeditación, alevosía y acuerdo con el cual habían actuado los asesinos ${ }^{37}$.

A la luz de estos datos parece claro que la existencia de nexos más allá del ámbito de la familia nuclear generaba un cúmulo de solidaridades que se encontraban en la raíz de dinámicas conflictivas a través de las cuales se manifestaba no solo el apoyo del linaje, sino también el de todo un conjunto de actores relacionados mediante vínculos de amistad o patrocinio. Así, es muy

34 AGS, RGS, abril de 1485, f. 194.

35 Ambos son mencionados como zapateros en 1498. SÁNCHEZ RUBIO, 1993: 426.

36 AGS, RGS, agosto de 1484, f. 63; diciembre de 1485, f. 88.

37 AGS, RGS, diciembre de 1485, f. 88. 
probable que el origen de esta violencia interna desatada entre musulmanes obedeciese, directa o indirectamente, al rechazo que generaba en la comunidad musulmana tanto la situación de privilegio del linaje Plaza como el apoyo a su posición prestado por parte de determinados cristianos poderosos con los que la familia sostenía vínculos clientelares, lo cual pudo ser interpretado por algunos correligionarios — quizás espoleados desde la propia aljama - como una traición a su identidad, aunque nos faltan elementos de juicio para dar una respuesta concluyente. Ello terminó desencadenando un correlato violento, acaso potenciado por elementos como la venganza de sangre tan imbricados en las estructuras sociales islámicas, tal y como se encargan de subrayar las compilaciones legislativas musulmanas producidas en Castilla durante los siglos XIV y XV ${ }^{38}$, a pesar de los intentos de la Monarquía y la legislación cristiana por regular e impedir dicha práctica mediante a la judicialización de las agresiones y homicidios ${ }^{39}$.

Dejando a un lado la dimensión más violenta de las relaciones sostenidas entre los Plaza y sus correligionarios, lo cierto es que los conflictos de la familia con la aljama todavía no habían concluido a fines de 1491, cuando Hamed de la Plaza volvía a solicitar en nombre de sus hermanos, hijos y sobrinos una sentencia del Consejo Real favorable al reconocimiento de sus privilegios. Según su declaración, la aljama habría obtenido finalmente en el pleito que libraba contra su familia, con syniestra relaçión, una sentencia de la Audiencia Real contraria al mantenimiento de la exención. Sin embargo, en el proceso posterior incoado ante el Consejo Real tras una nueva apelación presentada por Hamed, la institución mudéjar declinó comparecer, quizás sabedora de que su reivindicación esta vez no prosperaría. Ello motivó una resolución ejecutoria, dada el 29 de noviembre de 1491, en la cual se reconocía una vez más a la familia Plaza su franqueza tributaria y la obligación de la aljama de observarla y proceder a la devolución de las prendas tomadas ${ }^{40}$. La propia exención quedaba reflejada poco después en la cuenta presentada ante la Real Hacienda por los receptores del servicio y medio servicio pagado por los moros castellanos durante el bienio 1493-1494, entre cuyos asientos se incluía un descuento de $500 \mathrm{mrs}$ en la cantidad que debía abonar la aljama de

38 Dicha práctica aparece regulada en una compilación de leyes de moros del siglo XIV en unos términos bastante precisos: necesidad de juramento de los que supieran la verdad sobre el caso, prohibición de su práctica sobre los consanguíneos, y posibilidad de recibir compensación en dinero si el homicidio era involuntario, entre otras muchas disposiciones que no es preciso detallar aquí. GAYANGOS, 1853: 115-132. Ya en el siglo XV, el Breviario Sunni de Iça de Gebir afirmaba lo siguiente: quando uno matare a otro a sabiendas con espada, lança o piedra o con qualquiere cosa que sea, entreguenlo a sus enemigos que lo maten delante de la justiçia, por la bia que él mató al otro, y no tarden su muerte. GEBIR, 1853: 376.

39 LÓPEZ GÓMEZ, 2006: 242-249 y 540-583.

40 AGS, RGS, noviembre de 1491, f. 207. 
Trujillo correspondiente a un moro barbero, sin duda identificado con Hamed de la Plaza ${ }^{41}$.

Por otra parte, el texto de la provisión ejecutoria de noviembre de 1491 señala a la chançellería de los alcaldes de los fijosdalgo como la sala de la Audiencia Real encargada de pronunciar la sentencia recurrida, lo cual nos pone en la pista de la extensión - ciertamente minoritaria- a grupos no cristianos de situaciones análogas a la hidalguía de privilegio, asociadas a la franqueza de tributos directos y a la transmisión hereditaria de los derechos obtenidos por merced regia. En este sentido, la supresión del estatuto mudéjar en Castilla ordenada el 12 de febrero de 1502 por los reyes podría haber provocado un cambio en la situación privilegiada de la familia Plaza, habida cuenta de que con el tránsito de fe quedaba abolido el sistema fiscal específico de las comunidades musulmanas, cuyos antiguos miembros pasaron a quedar asimilados como pecheros en el régimen tributario propio de la población cristiana. Sin embargo, siguiendo una lógica bien conocida para otras comunidades, con la cual se trataba de impulsar el cambio de fe mediante la atracción de las elites y grupos rectores de la minoría, la Corona optó por mantener a los Plaza sus franquezas tributarias ${ }^{42}$. El 17 de marzo de 1502 los reyes otorgaban desde Zalamea una carta de privilegio y confirmación a petición de Fernán Alonso Villarejo, nuevamente convertido a nuestra santa fe católica que antes vos dezíades Abdallá Chicato, fijo de Yuçaf de la Plaça, vezino de la çibdad de Trujillo, en la cual se ratificaba a la familia en el disfrute de la exención general de pechos y otras prestaciones económicas otorgada por Juan II a su abue$1 \mathrm{o}^{43}$. Aunque el interesado mostraba su adhesión y la de los restantes descendientes de Mahomad de la Plaza a la nueva religión en términos de serviçio de Dios nuestro señor y a los reyes, y como forma de lograr el bien e salvaçión de su alma, Isabel y Fernando, sabedores de la insinceridad asociada al cambio de fe, pero conscientes de la necesidad de facilitar el proceso, se mostraron en todo momento favorables a mantener en su estatus a los grupos privilegiados mudéjares porque los otros que quedan por convertyr en la dicha çibdad con mejor voluntad fagan lo mismo. Con ello prolongaban la línea de actuación seguida tras la expulsión de los hebreos en 1492 con algunos de los judíos próximos a la corte que optaron por la permanencia en Castilla - como Abrahem Seneor, Rabí Mayr y sus familias-, que pasaron a quedar directamente incorporados a los escalones de la nobleza media urbana ${ }^{44}$. Ignoramos cuál fue a partir de este momento el destino de la familia Plaza de Trujillo, así

41 Cuenta del «servicio y medio servicio» de los años 1493-1494 rendida por Abrahem de San Salvador y Yuça de Toledo, AGS, CMC, $1^{a}$ ép., leg. 45, f. 10.

42 ORTEGO RICO, 24 (Madrid, 2011): 284-288.

43 AGS, MyP, leg. 94, f. 54.

44 LADERO QUESADA, CC/I (Madrid, 2003): 11-24. 
como el nivel de integración en la vida política ciudadana alcanzado por sus miembros. Sin embargo, lo cierto es que la conversión operada en 1502, lejos de representar un problema - más allá de las implicaciones estrictamente religiosas - contribuyó a liberar al linaje de la presión y exclusión a la que se había visto sometido durante la mayor parte del siglo XV por parte de sus correligionarios, logrando con ello la consolidación de una situación privilegiada que bien pudo favorecer su acceso a la condición de hidalguía que la exención tributaria otorgaba pasadas tres generaciones.

\section{Guadalajara y la Clientela mudéJar de los Mendoza: PRIVIlegios, FORMAS DE INTEGRACIÓN Y CONFLICTOS}

Frente a la ausencia de estudios referidos a la comunidad mudéjar trujillana, la aljama musulmana de Guadalajara cuenta con algunos trabajos específicos que han permitido profundizar tanto en sus aspectos estructurales como en las relaciones establecidas con las comunidades cristiana y judía, y con el poder urbano ${ }^{45}$. En este sentido, una de las notas distintivas de la comunidad islámica arriacense fue sin duda el estrecho vínculo que algunas de las familias a ella adscritas lograron establecer con el linaje Mendoza ${ }^{46}$, cuyo monopolio sobre el gobierno y los asuntos urbanos llegó a convertir la ciudad, que no llegó a perder su consideración jurídica como realengo ni su voto en Cortes, en un señorío nobiliario de facto ${ }^{47}$. Por ello, el análisis de la aljama de Guadalajara se revela como uno de los casos de estudio en los cuales mejor se aprecian, por un lado, las posibilidades de ascenso socio-político que brindaba a estos individuos y sus familias la inserción en redes clientelares asociadas al poder nobiliario; y por otro, la conflictividad que generaba en el seno de la aljama la consideración privilegiada en materia fiscal que estos grupos obtuvieron gracias a la mediación ofrecida por sus patronos como contrapartida a los servicios prestados. En este sentido, la situación no se mostraría diferente a la de otras aljamas — salvo por la abundancia e intensidad de los vínculos clientelares sostenidos - si no fuera porque más allá de la constatación de las vías de promoción que los lazos externos al grupo religioso habilitaban, existió un correlato conflictivo paralelo a nivel interno traducido en la formación de bandos ligados al ejercicio del poder jurisdiccional de la aljama que trataron de instrumentalizar en su favor las redes de dependencia anudadas con los poderes cristianos. De esta forma, ya no estaríamos hablando ex-

45 VIÑUALES FERREIRO, 2007: 501-512; 2009: 635-644.

46 ORTEGO RICO, 2009: 645-658.

47 LAYNA SERRANO, 1942. LÓPEZ VILLALBA, 5 (Madrid, 1992): 65-84. SÁNCHEZ PRIETO, 2001. 
clusivamente de la incorporación de mudéjares a un determinado bando-linaje urbano, y del impacto de esta circunstancia en el desarrollo de los conflictos internos de la aljama, sino también de la presencia de redes de dependencia clientelar articuladas entre los miembros de la comunidad y las elites mudéjares que operaban a nivel del Reino, representadas fundamentalmente por los alcaldes mayores de las aljamas de moros.

\section{Familias mudéjares privilegiadas y lazos clientelares}

Durante la década de 1430 tenemos las primeras menciones relativas a la concesión de privilegios de exención a algunas de las familias musulmanas afincadas en Guadalajara que, en el transcurso de pocas décadas, llegaron a desempeñar un papel más activo tanto en el seno de la aljama local como en el contexto de las luchas internas desarrolladas en el marco general del mudejarismo castellano en torno al ejercicio de la alcaldía mayor de las aljamas de moros de Castilla ${ }^{48}$. Probablemente los miembros de la conocida familia Belvis, originaria del reino de Aragón, donde sus antepasados habían desempeñado a lo largo del siglo XIV cargos de importancia tanto en la corte regia como a nivel judicial ${ }^{49}$, fueron los primeros en ver ratificado su estatus diferenciado mediante la exención tributaria. Tal y como figura en los registros de mercedes de época de Juan II, Yhaia de Belvis y su mujer gozaban desde el menos 1435 de una franqueza vitalicia de $700 \mathrm{mrs}$ en los tributos repartidos por la aljama de Guadalajara ${ }^{50}$, lo cual parece situarse en consonancia con el disfrute de la alcaldía mayor de los moros de Castilla otorgada por el monarca en algún momento de su reinado, según se hace constar años más tarde ${ }^{51}$. Aunque desconocemos el alcance efectivo de las relaciones que en aquel momento sostenían los Belvis con los Mendoza, lo cierto es que en 1441 Farax de Belvis, hijo de don Yahya, figura como criado al servicio de don Álvaro de Luna, pasando a incorporarse desde 1446 a la guardia morisca de Juan II, y a formar parte desde 1452 de la comisión encargada de distribuir el servicio y medio servicio entre las aljamas de moros de Castilla, como repartidor por Andalucía. El fulgurante ascenso de Farax de Belvis en el ámbito cortesano corrió paralelo a su inserción en los cuadros políticos musulmanes, tal y como certifica la concesión antes de 1451 de la alcaldía mayor de las aljamas de moros de Castilla que ya había ocupado su padre, y el desempeño de la alcaldía mayor local de

48 ECHEVARRÍA ARSUAGA, 14/1 (Madrid, 2003): 160-168. MOLÉNAT, 1999: 175-184.

49 Estudio de la rama castellana de la familia Belvis en ECHEVARRÍA ARSUAGA, 14/1 (Madrid, 2003): 152-160.

50 AGS, MyP, leg. 2, f. 406.

51 TORRES FONTES, 32 (Madrid, 1962): 175-180. 
la aljama de Guadalajara, en cuya posesión quedó ratificado en $1469^{52}$.

Para aquel entonces otras familias de la aljama mudéjar de Guadalajara gozaban también de interesantes exenciones tributarias. En unos casos obedecían a la prestación de servicios especializados a la Corona, convertida durante todo el siglo $\mathrm{XV}$ en una de las principales vías de acceso al poder político y al privilegio transitadas por los mudéjares castellanos. Ya el profesor Molénat advirtió, por ejemplo, de la presencia de parteras moras vecinas de Toledo en algunos de los nacimientos reales de fines del siglo XIV y comienzos del siglo XV, y de la gratificación de sus servicios mediante franquezas fiscales ${ }^{53}$. A estos datos se suma el de la exención de $500 \mathrm{mrs}$ en los pechos repartidos en la aljama de Guadalajara que disfrutaba en época de Juan II Marien, partera de la infanta, Yuça, Avymo y Haxa, sus hijos, y los maridos de estas últimas, a la sazón Mahomad de Arcos y Ali de Caravaña ${ }^{54}$. De igual forma, en los asientos de mercedes correspondientes a los años 1444-1450 también figura la franqueza otorgada a maestre Mahomad y su hermana Avimo, e el moro que fuere marido de la dicha Avyma por la cual se autorizaba a la aljama de Guadalajara una rebaja de $700 \mathrm{mrs}$ en los tributos repartidos ${ }^{55}$.

En otros casos estas exenciones respondían directamente a los vínculos de patronazgo establecidos con el linaje mendocino, tal y como evidencian las súplicas elevadas a Juan II por el marqués de Santillana Íñigo López de Mendoza en favor del reconocimiento de exenciones fiscales a determinados mudéjares de su clientela que, más allá de otorgar un nuevo estatus a sus beneficiarios, contribuyeron probablemente a fortalecer la fidelidad prestada al patrono, por cuanto en ella se fundamentaba la posición jurídico-fiscal alcanzada en el seno de la comunidad religiosa de adscripción. Así, el 20 de julio de 1441 Juan II otorgaba por quanto me lo suplicó e pidió por merçet Yñigo López de Mendoça, mi vasallo a maestre Abrahem de Medina, trapero vecino de Guadalajara, a su mujer doña Sol, y a sus hijos e hijas —entre los cuales se mencionan expresamente a Yahya y Mahomad de Medina - una exención que afectaba a todos los pechos y servicios repartidos a la aljama caracense, como veremos objeto de discordia años más tarde ${ }^{56}$. Poco después, maestre Abrahem de Medina suscribía en nombre de Íñigo López de Mendoza una sentencia arbitral dada en Coca el 2 de noviembre de 1442 relativa a la disputada herencia de la duquesa de Arjona doña Aldonza de Mendoza, hermanas-

52 ECHEVARRÍA ARSUAGA, 14/1 (Madrid, 2003): 157-159

53 MOLÉNAT, 2003a: 413-418.

54 AGS, MyP, leg. 2, f. 409r.

55 AGS, MyP, leg. 2, f. 410v; leg. 10-2, f. 155bis.

56 AGS, MyP, leg. 10, f. 105. 
tra del marqués de Santillana, lo cual prueba la estrecha relación sostenida entre ambos personajes ${ }^{57}$.

El vínculo clientelar con los Mendoza fue perpetuado por los descendientes de Abrahem de Medina. Su hijo Yahya de Medina figura en noviembre de 1469 junto al judío de Hita don Huda Alcaçar como procurador encargado de contabilizar 1.100 vasallos de Bornova, Henares y otros lugares que entraban en el trueque de Maqueda y la alcaldía mayor de Toledo, pertenecientes al obispo de Sigüenza Pedro González de Mendoza, por las fortalezas de Jadraque y Alcorlo, propiedad del arzobispo de Toledo Alonso Carrillo de Acuña, aunque fue relevado de sus funciones en enero de $1470^{58}$. Poco después, el 11 de agosto de 1475, el mismo Yahya de Medina, esta vez mencionado como criado del duque del Infantado Diego Hurtado de Mendoza, obtenía de Isabel y Fernando, gracias a la súplica elevada a los reyes por su patrono, confirmación de la franqueza otorgada por Juan II a sus padres don Abrahem de Medina y doña Sol, ya difuntos. En aquel momento Yahya era, al parecer, el único miembro de la familia capacitado para beneficiarse de la exención - que también afectaba a sus hijos Farax, Abrahem, Alí e Ismael, y a sus descendientes - ya que, según se explicita en el documento de confirmación, non quedó de vuestro padre e madre otro fijo que pudiese gozar de la dicha franqueza a ellos dada ${ }^{59}$.

Como en el caso de Trujillo, la presencia de estos grupos privilegiados no fue bien acogida en la comunidad musulmana de Guadalajara, remisa a reconocer sus exenciones. Ello determinó la presentación de una queja ante el Consejo Real por parte de Yahya de Medina, y la apertura de un proceso judicial sustanciado ante el doctor Ariño Ramírez de Zamora cuya sentencia pronunciada el 20 de octubre de 1477, resultó desfavorable a los intereses de la aljama ${ }^{60}$. Con ello los miembros de la familia lograban preservar una situación privilegiada estrechamente ligada al vínculo clientelar mantenido con los Mendoza, reproducido generación tras generación. No en vano, algunos años después Farax de Medina - hijo de Yahya de Medina - aparece relacionado con Bernardino Suárez de Mendoza, II conde de Coruña, en cuya casa ejercía la función de contador en febrero de $1495^{61}$.

57 RAH, Colección Salazar y Castro, O-4, ff. 46-48v.

58 VILLALBA RUIZ DE TOLEDO, 1 (Madrid, 1999): 30, 38 у 50.

59 AGS, MyP, leg. 80, f. 22.

60 AGS, RGS, octubre de 1477, f. 132.

${ }^{61}$ AGS, RGS, febrero de 1495, f. 519. 


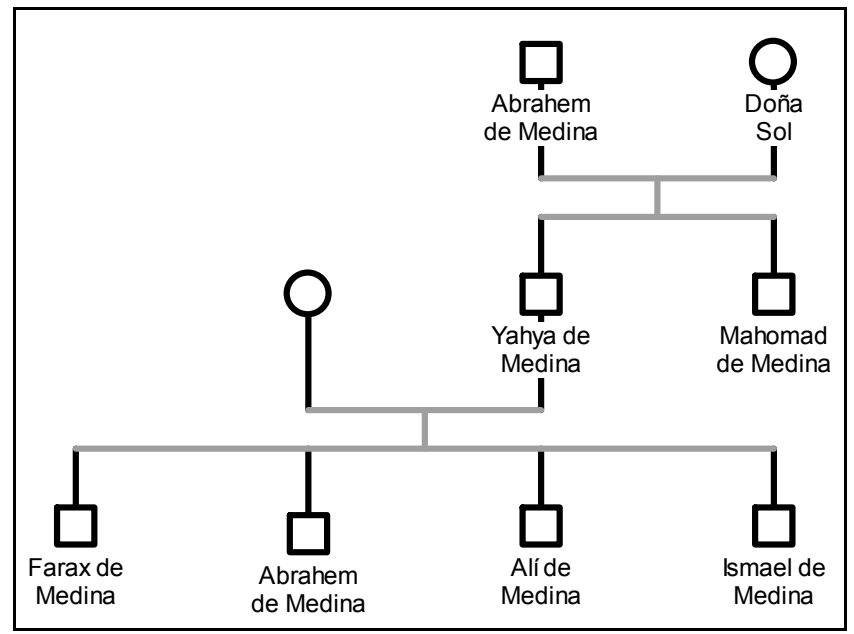

TABLA 2. Familia Medina de Guadalajara

Por otra parte, la labor de mediación del linaje ante el poder regio también se extendió al ámbito institucional propio de la minoría, que era el que mayores ventajas podía ofrecer en relación a las formas de control y dominio político de la comunidad religiosa. Así, es bien sabido que el polémico nombramiento de Farax de Belvis como alcalde mayor de las aljamas de moros de Castilla realizado por los reyes el 20 de octubre de 1475 fue posible, en gran medida, gracias a la súplica elevada a los Reyes Católicos por parte del I duque del Infantado Diego Hurtado de Mendoza ${ }^{62}$ en un momento marcado por la defensa de la legitimidad de Isabel I realizada por su linaje. En este sentido, la integración de la familia Belvis en la clientela mendocina, bien constatada desde este momento, aunque con toda seguridad databa de tiempos anteriores, tuvo otras manifestaciones específicas relacionadas con la gestión del patrimonio y rentas señoriales, tareas en las cuales intervinieron de forma recurrente distintos componentes de la comunidad musulmana arriacense, entre los cuales destacan los miembros de la familia Pullate. Ya en 1454 un Abda1la Pullate es mencionado en las actas del concejo de Guadalajara como mayordomo del marqués de Santillana ${ }^{63}$, mientras que en 1473 un personaje homónimo - al que identificamos con el mencionado mayordomo- figura como recaudador del servicio y montazgo de los ganados del Reino junto al financiero Luis de Alcalá $^{64}$. Por otro lado, el 10 de mayo de 1479 se firmaba

62 TORRES FONTES, 32 (Madrid, 1962): 177.

63 LÓPEZ VILLALBA, 1997: 88.

64 AMG, Caja 4, doc. 142635. 
en Guadalajara una capitulación entre el II duque del Infantado Íñigo López de Mendoza, y el contador de su padre, a la sazón Hamete Pullate, relativa a las rentas integradas en la hacienda señorial que este último había tomado en arriendo de Diego Hurtado de Mendoza, I duque del Infantado, fallecido en enero de 1479. Dicha capitulación implicaba una renegociación del precio de arrendamiento acordado inicialmente con Hamete Pullate toda vez que el nuevo duque optó por entregar a su hermano don Juan de Mendoza parte de las rentas que el contador mudéjar había aceptado gestionar anteriormente. Más allá de las cuestiones técnicas asociadas al nuevo contrato suscrito, el documento resulta muy expresivo de la importancia que algunos miembros de la clientela mudéjar llegaron a alcanzar en la gestión de los asuntos económicos del linaje, a la cual antes hacíamos referencia. Así, tanto Farax de Belvis como el mayordomo Abdalla Pullate - a buen seguro familiar del contador Hamete Pullatefueron los encargados de determinar las nuevas condiciones del arrendamiento junto al secretario ducal Diego García de Guadalajara y los bachilleres Alfón y Diego de Medina, aunque, según condición estipulada por el contador, el concurso de sus dos correligionarios sería imprescindible en la resolución ${ }^{65}$.

Al margen de las relaciones estrechadas entre los Belvis y los Pullate, todo apunta a que la prestación de servicios de índole económica en el marco de la administración de la casa nobiliaria se mostraba, de forma aislada, como un vínculo mucho más frágil que el establecido en términos de estricto patrocinio. Quizás por ello, los miembros de la familia Pullate, ninguno de los cuales figura entre los beneficiarios de exenciones fiscales, se vieron incursos a lo largo de la década de 1480 en diversos pleitos relacionados con la gestión financiera sin que el apoyo del linaje mendocino se expresase, al menos de forma aparente. Por ejemplo, en marzo de 1480 Isabel Enríquez, duquesa viuda del Infantado, reclamaba a Hamete Pullate el pago de 150 cántaros de vino — o $60 \mathrm{mrs}$ por cántaro - que su esposo Diego Hurtado de Mendoza había librado en él «çiertos años pasados» ${ }^{66}$. En ese momento, el mudéjar ya no ejercía las funciones de contador de la casa ducal, probablemente como consecuencia de una reestructuración del personal llevada a cabo tras la muerte de Diego Hurtado. Sí continuó prestando sus servicios cortesanos Abdalla Pullate, mencionado en 1485 como mayordomo del II duque del Infantado Íñigo López de Mendoza y de su hermano don Juan de Mendoza ${ }^{67}$, aunque ello no le eximió de problemas derivados de su participación en actividades financieras ${ }^{68}$.

En este sentido, el caso de los Pullate muestra cómo no todos los vínculos sostenidos entre los miembros de la comunidad musulmana y el linaje nobi-

65 SNAHN, Osuna, carp. 1670, doc. 1 (3).

66 AGS, RGS, marzo de 1480, f. 418.

67 AGS, RGS, diciembre de 1485, f. 129.

68 ARCV, Ejecutorias, Caja 27, exp. 2. 
liario quedaron traducidos en la concesión de privilegios de exención tributaria como los señalados para el caso de los Belvis o los Medina, quizás reservados para aquellos servidores más cercanos. Por ejemplo, Çulemán Xabi, vecino de Guadalajara, y su mujer, obtenían a petición de la duquesa del Infantado el 30 de enero de 1488 una franqueza de $6.000 \mathrm{mrs}$ en el pago de alcabalas por las cosas que vendieran en la casa, tienda y botica que tenían en Guadalajara, lo cual pone de manifiesto una vez más las posibilidades que la intermediación nobiliaria habilitaba de cara a lograr la exención ${ }^{69}$. Por su parte, el 14 de abril del mismo año los reyes otorgaban a Ali de Mendoza Alança, a su mujer e hijos, y a sus descendientes, una franqueza en los pechos y derechos abonados por la aljama, por quanto nos lo suplicó e pidió por merçed el reverendísimo Cardenal d'España don Pedro González de Mendoza ${ }^{70}$. En este último caso, más allá del estrecho vínculo clientelar que evidencia la adopción del apellido del linaje por parte del mudéjar, siguiendo una práctica utilizada posteriormente por muchos moriscos tras aceptar el bautismo ${ }^{71}$, el patrocinio ejercido por el Cardenal quedó también explicitado en la protección dispensada a su cliente. De hecho, el 30 de abril de 1490 los reyes otorgaban su perdón al mismo Ali de Mendoza por su activa participación en la conversión al Islam del judío de quince años Salamón Çeano, en la cual también intervinieron otros mudéjares - entre ellos el alfaquí de Guadalajara Çide Açán-, denunciados por el hebreo Mayr aben Arroyo ${ }^{72}$.

\section{Conflictos fiscales y conflictos políticos: luchas banderizas y redes de po- der en la aljama de Guadalajara}

Como en otros casos, la situación privilegiada que disfrutaban estas familias musulmanas tuvo importantes consecuencias en el seno de la aljama, conscientes algunos de sus miembros del amparo que ofrecían las estructuras de agregación vertical en las cuales se integraban sus correligionarios. Ello provocaba injerencias de los grupos urbanos que ejercían el poder en conflictos que afectaban a los miembros de la comunidad musulmana, tal y como evidencia la carta de seguro otorgada por los reyes el 16 de febrero de 1489 en favor de maestre Hamad Atujabí y maestre Ali Toledano, moros vecinos de Guadalajara. Al parecer, ambos mudéjares temían represalias violentas después de haber acudido a la corte regia para tratar ciertas cuestiones, a cau-

69 AGS, MyP, leg. 122, f. 1.

70 AGS, MyP, leg. 81, f. 5.

71 LADERO QUESADA, 1989b: 144.

72 AGS, RGS, abril de 1490, f. 55. VILLALBA RUIZ DE TOLEDO, 1 (Madrid, 1999): 338-340. AGS, RGS, mayo de 1490, f. 400. SUÁREZ FERNÁNDEZ, 1964: 340-341. 
sa de lo cual algunas personas, asy christianos como moros, les tyenen odio e enemistad $^{73}$. En este sentido, el origen de la tensión sin duda tenía que ver con el pleito que desde al menos 1489 sostenían ambos personajes con Abdalla Pullate por la herencia de doña Fátima, tía de sus mujeres y viuda de Abrahem de Medina. Sin entrar a valorar los pormenores del pleito ${ }^{74}$, cuyo fallo definitivo en junio de 1489 resultó desfavorable a ambas partes, su análisis tiene interés por cuanto, además de constatar los nexos familiares que unían a las familias Medina y Pullate, permite apreciar cómo la resolución preliminar del litigio de forma contraria a los intereses de unos mudéjares como los Pullate o los Medina, integrados en la clientela mendocina, era susceptible de generar una reacción de apoyo en su favor por parte de los grupos que ejercían el poder en la ciudad, a los cuales se encontraban ligados, evidenciando con ello las grandes posibilidades que el sostenimiento de vínculos externos a la comunidad religiosa habilitaba a la hora de mantener una posición de fortaleza.

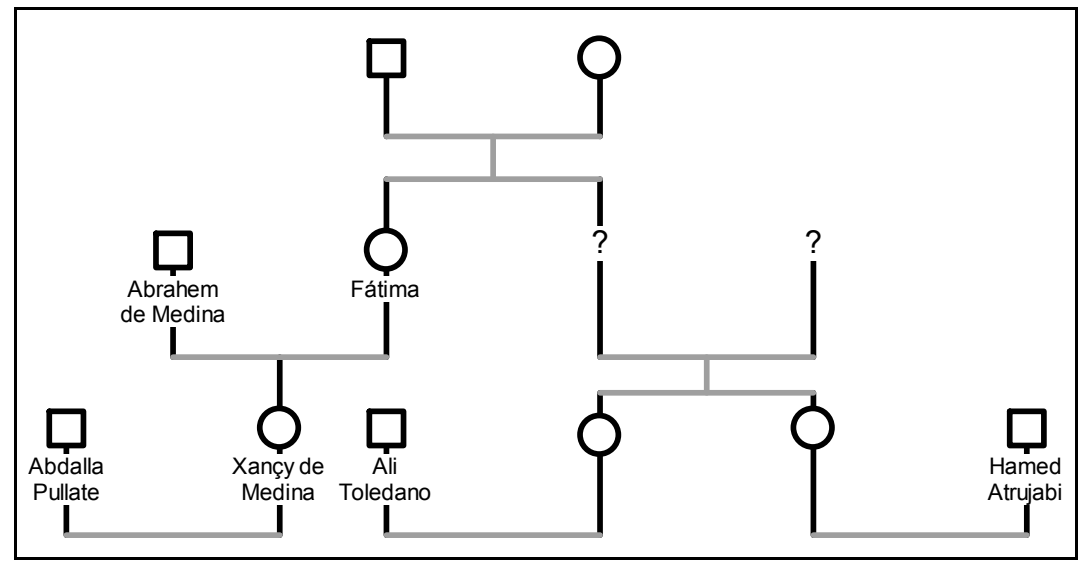

TABLA 3. Genealogía del pleito por la herencia de doña Fátima

Al margen de esta disputa, el año 1491 marcó un punto culminante en las relaciones de conflicto vividas en el seno de la comunidad musulmana de Guadalajara, cuya problemática fiscal actuó una vez más como caja de resonancia de las tensiones internas. Así, tras el primer conflicto desarrollado en 1477 en relación a la franqueza tributaria disfrutada por Yahya de Medina y

73 AGS, RGS, febrero de 1489, f. 90.

74 AGS, RGS, febrero de 1489, f. 297; marzo de 1489, ff. 105 y 257; junio de 1489, f. 54. 
su familia, resuelto de forma favorable a este último, la aljama presentó de nuevo en 1491 un conjunto de reclamaciones contrarias al derecho de los exentos a disfrutar de sus privilegios, cuyo trasfondo político se encontraba asociado a la nueva situación que se abría en el plano jurisdiccional tras el fallecimiento del alcalde mayor de la aljama Farax de Belvis antes del 20 de marzo de $1491^{75}$. El 15 de junio de 1491 los reyes ordenaban a los alcaldes cristianos de Guadalajara, a petición de la aljama mora arriacense, la realización de una pesquisa relativa a las franquezas otorgadas por Juan II a Abrahem de Medina, su mujer e hijos, y a maestre Farax Çarafi, su mujer Fátima y sus hijos, y por otro, las concedidas por Isabel y Fernando a Ali de Mendoza, su mujer, hijos y descendientes. En este sentido, a pesar de los descuentos anuales reconocidos por la Corona para compensar estas franquezas, la aljama denunciaba el agravio que sufría pues...

...los susodichos que asy tienen los dichos previllejos son los más ricos e más cabdalosos e de mayores faziendas, e a quien por respeto de la dicha fazienda que cada uno d'ellos tiene avían de pagar la mitad de todos los repartimientos e otras cosas que a la dicha aljama se echasen e repartiesen, de manera que todo lo que ellos avían de pagar carga sobre los pobres e huérfanos e miserables personas de la dicha aljama, e que fasta aquí con mucha fuerza e grand pérdida de sus faziendas ha conplido e pagado todos los repartimientos e otras cosas que les han seydo repartidas e de que ellos nos avemos querido servir para la guerra de los moros como para otras cosas en que los susodichos nin algunos de ellos non han pagado cosa alguna, en lo qual sy asi oviese a pagar diz que la dicha aljama resçibiría mucho agravio e daño ${ }^{76}$.

Aunque ignoramos el resultado de la pesquisa, lo cierto es que a la altura de 1491 la comunidad mudéjar de Guadalajara se encontraba fuertemente polarizada entre los partidarios de una mayor equidad en los repartos fiscales y los grupos que, como consecuencia del privilegio o de la riqueza acumulada, se mostraban escasamente solidarios con sus correligionarios en lo que se refería al pago de tributos. Así lo prueba, en primer lugar, la queja planteada hacia las mismas fechas por Alí Guní, también vecino de Guadalajara que, después de medrar económicamente, reclamaba el cumplimiento de cierto estatuto aprobado por la aljama arriacense hacia 1437, según el cual...

...aunque algund moro toviese alguna más hazienda que otros, no fuese encabeçado ni enpadronado por sy solo, salvo que a lo menos al tal pechero posiesen en tal suma y contya de pecha que en ella podiese tener tres o quatro moros de la dicha aljama con quien él fuese ygualado e relego en la misma contya de pecha.

75 Aparece como fallecido en AGS, RGS, marzo de 1491, f. 60.

76 AGS, RGS, junio de 1491, f. 64. 
En definitiva, la exigencia del mudéjar pasaba porque su desahogada posición económica no supusiera un incremento de sus responsabilidades tributarias derivado de su inclusión en los padrones realizados por la aljama constituyendo el único individuo dentro de un tramo fiscal más gravado. En su razonamiento, el propio afectado llegaba a señalar la necesidad de aplicar el régimen vigente en la mayor parte de los concejos castellanos y en otras comunidades mudéjares, según el cual a partir de un determinado nivel de riqueza todos los pecheros debían quedar asimilados sin que la deuda tributaria sufriera incremento alguno pues, tal y como apuntaba, los ricos syenpre, demás de los pecheros, nos serben en otras muchas cosas, y aún aprovecha a los pueblos y comunidades donde biven ${ }^{77}$. Por otro lado, el 15 de noviembre de 1491 los reyes comisionaban al licenciado Diego López, juez de residencia de la villa de Madrid, para llevar a cabo una nueva averiguación, esta vez a raíz de la denuncia planteada por Hamete Calderero, vecino de Guadalajara y procurador de su aljama, en la cual se advertía de la exención disfrutada por parte de algunos miembros de la comunidad que con favores de algunas personas e cavalleros e vezinos de la dicha çibdad rechazaban contribuir en los repartimientos, a pesar del principio de proporcionalidad vinculada a la riqueza individual/familiar por el cual se había guiado hasta el momento la aljama arriacense en sus repartos fiscales ${ }^{78}$.

Más allá de estas reclamaciones, consideramos que la problemática tributaria planteada no se puede desvincular de las luchas políticas internas desatadas en la aljama de Guadalajara tras la muerte de Farax de Belvis, su alcalde mayor y uno de los mudéjares que habían disputado al toledano Abrahem Xarafí la alcaldía mayor de las aljamas de moros de Castilla. Sin entrar a valorar los pormenores del conflicto, surgido como es bien sabido de la provisión simultánea del cargo a varios beneficiarios, la sentencia dada por la $\mathrm{Au}-$ diencia Real en 1490, en la cual se privaba a Farax de Belvis de la alcaldía mayor de las aljamas de moros de Castilla en beneficio del Xarafí, reconocía, sin embargo, la continuidad del primero como alcalde mayor de la aljama de Guadalajara $^{79}$. La Audiencia no solo se mostró favorable a Abraham Xarafí en este litigio, sino también en los sucesivos que surgieron por la negativa de otras aljamas mudéjares a aceptar su jurisdicción. Entre ellos alcanzó un relevancia especial el pleito que mantuvo con Yuçaf Engeñero, vecino de Guadalajara y beneficiario tras la muerte de Farax de Belvis — por designación de este último - de la alcaldía mayor local y del disputado oficio de alcalde mayor de las aljamas de Castilla, cuya sentencia dada por la Audiencia en julio de 1492 supuso el reconocimiento de Abraham Xarafí como alcalde mayor de

77 AGS, RGS, junio de 1491, f. 46.

78 AGS, RGS, noviembre de 1491, f. 64.

79 MOLÉNAT, 1999: 179. ECHEVARRÍA ARSUAGA, 14/1 (Madrid, 2003): 165-166. 
las aljamas de Castilla y de su capacidad para nombrar delegados afines en la aljama de Guadalajara, en lo que se puede entender como un intento por afianzar su poder en una comunidad cuyas élites privilegiadas se habían mostrado especialmente díscolas y beligerantes a aceptar su jurisdicción ${ }^{80}$.

En este sentido, hay que tener en cuenta que el desempeño del cargo de alcalde mayor de las aljamas de Castilla de forma simultánea por parte de varios beneficiarios legitimados en sus funciones por el poder real, generaba la necesidad de buscar apoyos en el seno de cada aljama, traducidos en el nombramiento de lugartenientes o alcaldes locales afines, facultad inherente al ejercicio del cargo ${ }^{81}$. De esta forma, estos vínculos en términos de clientelismo se convirtieron en el núcleo medular de las relaciones establecidas entre los alcaldes mayores de las aljamas de Castilla y las elites mudéjares locales, pero también en una forma de integración en un determinado grupo de poder, como garantía de supervivencia política. Con ello, estos grupos seguían parámetros de comportamiento muy similares a los puestos en práctica tradicionalmente por la nobleza en sus luchas políticas, como la conformación de ligas y bandos enfrentados, aunque con un menor grado de institucionalización.

Esta situación de división interna era especialmente visible en la aljama de Guadalajara, donde la presencia de un amplio grupo de mudéjares privilegiados, que además gozaba de la protección de los poderes cristianos, generaba un evidente rechazo entre buena parte de sus correligionarios, que probablemente optaron por buscar apoyos exteriores a la comunidad local entre aquellos mudéjares notables — como Abrahem Xarafí- enfrentados políticamente al sector de la comunidad liderado por los Belvis. En este sentido, mientras que el nombramiento de Yuçaf Engeñero como alcalde mayor de la aljama realizado en marzo de 1491 fue acatado y reconocido por el regimiento y la justicia urbana, parte de la comunidad musulmana — que hacía oír su voz en el seno de la aljama - manifestó su oposición a reconocerle como tal. Ello motivó la queja de Engeñero y la entrega de una sobrecarta en agosto de 1491 en la cual la Corona le ratificaba en el ejercicio del $\operatorname{cargo}^{82}$, a pesar de que para ese momento Abrahem Xarafí, aprovechando la muerte de Farax de Belvis, ya había nombrado a Hamete Calderero, moro vecino de Guadalajara, como lugarteniente en la aljama arriancense, abriendo con ello una profunda brecha en el seno de la comunidad, expresada a través de un correlato fiscal ${ }^{83}$.

El nombramiento de un lugarteniente por parte de Abrahem Xarafí fue contestado por Yuçaf Engeñero ante la aljama local y posteriormente por vía judicial ante la justicia urbana de Guadalajara, que probablemente falló en

80 AGS, RGS, marzo de 1491, f. 60. ARCV, Ejecutorias, Caja 45, exp. 5, ff. 4v-5v.

81 TORRES FONTES, 1969: 158.

82 AGS, RGS, agosto de 1491, f. 345.

83 ARCV, Ejecutorias, Caja 45, exp. 5, f. 2r. 
favor del Engeñero ${ }^{84}$ habida cuenta de su mediatización por parte de los Mendoza, encargados de nombrar a los alcaldes de las alzadas ${ }^{85}$. Ello motivó la presentación de un recurso de apelación por parte de Abrahem Xarafí ante la Audiencia en el cual se exigía la revocación de la merced de la alcaldía mayor de las aljamas de moros concedida a Yuçaf Engeñero, así como la ratificación de Hamete Calderero en el cargo de lugarteniente, ya que...

...el dicho maestre Yuça Engeñero por virtud de la dicha nuestra carta de merçed perturbava al dicho maestre Hamete Calderero, su lugarteniente, en su posesyón y le avía fecho çiertos abtos e requerimientos e emplazamientos con la dicha merçed $^{86}$.

Quizás convenga recordar que precisamente este Hamete Calderero, que se mantuvo al frente de la alcaldía mayor de la aljama arriacense hasta al menos junio de $1501^{87}$, fue el encargado de presentar ante el poder real como procurador de la aljama la queja referida a la exención tributaria que algunos mudéjares disfrutaban con favores de algunas personas e cavalleros e vezinos de la dicha çibdad a la que ya hemos hecho alusión ${ }^{88}$. A nuestro modo de ver no se trataba de una denuncia inocente, pues detrás del discurso «clasista» del lugarteniente - la exención repercutía en el incremento de la presión fiscal sobre los grupos más desfavorecidos de la comunidad - probablemente se escondía un ataque directo al grupo de poder representado por los antiguos partidarios de los Belvis y por Yuçaf Engeñero, estrechamente vinculados al linaje mendocino y bien relacionados con el concejo ${ }^{89}$. Igualmente, tampoco resulta extraño que Alí Guni o Gumir, mencionado en julio de 1496 como segundo esposo de doña Marien, viuda de Farax de Belvis ${ }^{90}$, recibiera presiones destinadas a elevar su cuota tributaria, lo cual motivó la ya mencionada queja antes los reyes en relación a los cambios introducidos por la aljama en la forma de pechar ${ }^{91}$.

Ignoramos si estas presiones y conflictos hacia los miembros de la clientela mendocina tuvieron una respuesta efectiva por parte del linaje, aprove-

${ }^{84}$ ARCV, Ejecutorias, Caja 45, exp. 5, f. 1r.

85 En julio de 1464 Enrique IV otorgaba a Diego Hurtado de Mendoza, entre otros oficios urbanos, la alcaldía de las alzadas de Guadalajara en juro de heredad. SNAHN, Osuna, Caja 1875, doc. 2 (1-6).

86 ARCV, Ejecutorias, Caja 45, exp. 5, f. 2v.

87 ARCV, Ejecutorias, Caja 335, exp. 61, f. 3r.

88 AGS, RGS, noviembre de 1491, f. 64.

89 Un Mahomad Engeñero fue alarife del concejo hasta su muerte en 1485. En el Libro de actas del concejo de Guadalajara consta su sustitución por su hermano, de nombre desconocido, que bien pudiera ser este Yuça Engeñero. LÓPEZ VILLALBA, 1997: 248-249.

90 ARCV, Ejecutorias, Caja 102, exp. 6.

91 AGS, RGS, noviembre de 1491, f. 63. 
chando el poder efectivo del que gozaba en la ciudad y los resortes asociados a su posición de fortaleza. No obstante, resulta muy elocuente la queja presentada por el moro Abdalla, vecino de Guadalajara, en la cual denunciaba antes de marzo de 1496 ante los reyes cómo...

\begin{abstract}
«...estando defendido e vedado por las leyes de nuestros reygnos que ningund cavallero ni otra persona d'ellos no tome posendas para sy nin para los suyos en las çibdades e villas e logares de nuestra Corona Real, diz que sin enbargo d'ello los aposentadores del duque del Ynfantadgo y del arçobispo de Sevilla y de don Juan de León, quando a la dicha çibdad de Guadalajara vienen, hazen muchos agravios e sinrazones aposentando en su casa los huéspedes que quieren y sacándole la ropa de su casa por fuerça e contra su voluntad $»^{92}$.
\end{abstract}

¿Era esta una de las réplicas articuladas por parte del linaje mendocino ante los agravios que sus clientes moros recibían por parte de su comunidad religiosa de adscripción? Aunque carecemos de una respuesta definitiva, lo cierto es que el texto refleja de forma muy expresiva el papel desempeñado por el linaje como «fiel» de una balanza que, en función de la relación anudada, en unas ocasiones se inclinaba hacia la búsqueda del privilegio de sus clientes, y en otras basculaba hacia el establecimiento de gravámenes y exacciones que contribuían a deteriorar la ya de por sí frágil situación en que se hallaban muchos mudéjares.

\title{
CONCLUSIONES
}

Si algo ponen de manifiesto los casos analizados es lo lejos que todavía estamos de conocer en toda su complejidad el impacto efectivo que ejercía la fiscalidad con la que los poderes cristianos gravaban a las comunidades mudéjares castellanas tanto en su estructuración y jerarquización interna como en el sostenimiento y amplificación de dinámicas conflictivas, tuvieran o no estas un origen propiamente fiscal. En este sentido, los dos ejemplos valorados revelan, en primer lugar, la presencia de unos patrones de conducta semejantes en lo que atañe a las fórmulas de acceso de determinados mudéjares al privilegio, condicionadas por la existencia previa de nexos clientelares con poderes cristianos próximos a la Corona los cuales, mediante la labor de intermediación y protección dispensada podrían retroalimentar la relación de dependencia estrechada. Por otra parte, la inserción de estos mudéjares privilegiados en estructuras verticales de agregación político-social urbana es evidente que introducía distorsiones en sus relaciones con los restantes miem-

92 AGS, CCA, Personas, leg. 1-1, f. 19. 
bros de la comunidad religiosa - cuyo cauce institucional de representación política era la aljama - tendentes a romper los marcos de solidaridad que generaba el vínculo religioso compartido a través del cual se definían los límites culturales y jurídicos del grupo, aunque no los marcos de relación social de sus integrantes. Esta ruptura quedaba evidenciada en las fuertes presiones soportadas en el marco comunitario por parte de los grupos y familias que gozaban de exenciones tributarias, en función de los desequilibrios que estas franquezas provocaban a la hora de realizar un reparto tributario equitativo basado en el patrimonio y, sobre todo, de la incorporación de diferencias de estatus cuyo origen se encontraba habitualmente desvinculado de elementos endógenos como la formación religiosa, el prestigio o la capacidad de liderazgo demostrada.

En defensa de sus intereses, ambas partes — privilegiados y aljamas- recurrieron a fórmulas similares que pasaban, en primer lugar, por el recurso al arbitraje de la Corona y de las instituciones judiciales cristianas, hecho que subraya por un lado la dependencia de los mudéjares castellanos y sus estructuras políticas del poder que toleraba su continuidad, y por otro, la instrumentalización a la que se veía sometida la Corona por parte de estos grupos a la hora de legitimar los derechos alegados. No obstante, cuando esto último no era factible, o como respuesta a situaciones de conflicto abierto con la aljama, los sectores privilegiados no dudaron en recurrir al concurso de la red clientelar en la cual se hallaban inmersos para hacer valer sus posiciones, o defender el estatus adquirido, mediante vías coactivas, tal y como se ha podido constatar en los casos de Trujillo y Guadalajara. En este sentido, el ejemplo de Guadalajara revela además cómo la propia aljama, enfrentada a las minorías exentas de tributación que formaban parte de la clientela mendocina, aprovechó las disputas existentes en el seno de la élite judicial mudéjar castellana para aplicar su modelo de reparto tributario gracias a su posicionamiento en favor de la facción liderada por Abrahem Xarafí, lo cual demuestra que, más allá de la integración del elemento mudéjar en clientelas urbanas, también existieron estructuras de agregación política formadas exclusivamente por miembros de la minoría musulmana, cuyo estudio todavía está por realizar. Por ello, consideramos esencial seguir profundizando, hasta donde las fuentes permitan, en el conocimiento de la realidad interna de las aljamas mudéjares castellanas y en los vínculos endógenos y exógenos establecidos por sus miembros tanto en el espacio local como a nivel de Reino, a la hora de valorar dinámicas conflictivas en las cuales la reclamación fiscal que se observa en muchas aljamas, lejos de responder únicamente a un problema en el reparto de la carga tributaria, servía también como elemento de confrontación política. 


\section{BIBLIOGRAFÍA}

Abboud-Haggar, Soha, «Leyes musulmanas y fiscalidad mudéjar», Finanzas y fiscalidad municipal. V Congreso de Estudios Medievales, León, Fundación SánchezAlbornoz, 1997: 169-205.

Abboud-Haggar, Soha, «Conflicto de jurisdicción en un pleito entre mudéjares. Ágreda 1501», Cuadernos de Historia del Derecho, 6 (Madrid, 1999): 415-432.

Abboud-Haggar, Soha, «Precedentes andalusíes en la fiscalidad de las comunidades mudéjares», En la España Medieval, 31 (Madrid, 2008): 475-512.

Catlos, Brian A., The Victors and the Vanquished. Christians and Muslims of Catalonia and Aragon, 1050-1300, Cambridge, Cambridge University Press, 2004.

Catlos, Brian A., «Privilegio y poder en Aragón: el auge y declive del «çavalaquem» Çalema», Ana Echevarría Arsuaga (coord.), Biografias mudéjares o La experiencia de ser minoría: biografías islámicas en la España cristiana, Madrid, CSIC, 2008: 133-182.

Echevarría Arsuaga, Ana, «Las aljamas mudéjares castellanas en el siglo XV: redes de poder y conflictos internos», Espacio, Tiempo y Forma. Serie III, $H^{a}$ Medieval, 14 (Madrid, 2001): 93-112.

Echevarría Arsuaga, Ana, «De cadí a alcalde mayor. La élite judicial mudéjar en el siglo XV (I)», Al-Qantara, 14/1 (Madrid, 2003): 139-168.

Echevarría Arsuaga, Ana, «Los mudéjares: ¿minoría, marginados o "grupos culturales privilegiados"?», Medievalismo, 18 (Madrid, 2008): 45-66.

Fernández-Daza Álvarez, Carmen, «Linajes trujillanos y cargos concejiles en el siglo XV», En la España Medieval, 6, (Madrid, 1985): 419-432.

Ferrer i Mallol, María Teresa, «Francos, pero excluidos de la mezquita y del cementerio: los Bellito y los Galip de la morería de Zaragoza», María del Val González de la Peña (coord.), Estudios en memoria del Profesor Dr. Carlos Sáez. Homenaje, Alcalá de Henares, Universidad de Alcalá-Servicio de Publicaciones, 2007: 341-352.

Gayangos, Pascual de (ed.), «Leyes de moros», en Memorial Histórico Español, Madrid, Real Academia de la Historia, 1853, V: 11-246.

Gebir, Iça de, «Suma de los principales mandamientos y devedamientos de la ley y çunna», Memorial Histórico Español, Madrid, Real Academia de la Historia, 1853, V: 247-422.

Ladero Quesada, Miguel Ángel, «Datos demográficos sobre los musulmanes de Granada y Castilla en el siglo XV», Anuario de Estudios Medievales, 8 (Barcelona, 1972-1973): 481-490.

Ladero Quesada, Miguel Ángel, «Los mudéjares de Castilla en la Baja Edad Media», Los mudéjares de Castilla y otros estudios de historia medieval andaluza, Granada, Universidad de Granada, 1989a: 11-132.

Ladero Quesada, Miguel Ángel, «Nóminas de conversos granadinos (1499-1500)», Los mudéjares de Castilla y otros estudios de historia medieval andaluza, Granada, Universidad de Granada, 1989b: 133-168. 
Ladero Quesada, Miguel Ángel, «Linajes, bandos y parcialidades en la vida política de las ciudades castellanas (siglos XIV y XV)», Bandos y querellas dinásticas en España al final de la Edad Media, Paris, 1991: 105-134.

Ladero Quesada, Miguel Ángel, «"Derechos de oficiales” y “derechos ciertos” en la Hacienda real de Castilla (año 1430)», Mayurqa, 27 (Palma de Mallorca, 2001): 11-23.

Ladero Quesada, Miguel Ángel, «Coronel, 1492: de la aristocracia judía a la nobleza cristiana en la España de los Reyes Católicos», Boletín de la Real Academia de la Historia, CC/I (Madrid, 2003): 11-24.

Layna Serrano, Francisco, Historia de Guadalajara y sus Mendozas en los siglos XV y XVI, Madrid, Instituto Jerónimo Zurita, 1942, 4 vols.

Lopes de Barros, María Filomena, «Las élites mudéjares del reino portugués», Ana Echevarría Arsuaga (coord.), Biografías mudéjares o la experiencia de ser minoría: biografías islámicas en la España cristiana, Madrid, CSIC, 2008: 101-132.

López Gómez, Óscar, Violencia urbana y paz regia: el fin de la época medieval en Toledo (1465-1522). Tesis doctoral inédita, Universidad de Castilla La Mancha, Departamento de Historia, 2006.

López Villalba, José Miguel, «Concejo abierto, regimiento y corregimiento en Guadalajara (1346-1546)», Espacio, Tiempo y Forma. Serie III, Historia medieval, 5 (Madrid, 1992): 65-84.

López Villalba, José Miguel, Las actas de sesiones del concejo medieval de Guadalajara, Madrid, Universidad Nacional de Educación a Distancia, 1997.

Molénat, Jean-Pierre, «À propos d'Abrahen Xarafí: les alcaldes mayores de los moros de Castille au temps des Rois Catholiques», VII Simposio Internacional de Mudejarismo, Teruel, Instituto de Estudios Turolenses-Centro de Estudios Mudéjares, 1999: 175-184.

Molénat, Jean-Pierre, «L'Élite Mudéjare dans la Péninsule Ibérique Médievale», Filipe Themudo Barata (ed.), Elites e redes clientelares na Idade Média, Lisboa, Edições Colibri, 2001: 45-53.

Molénat, Jean-Pierre, «Privilégiées ou poursuivies: quatre sage-femmes musulmanes dans la Castille du XV $\mathrm{XV}^{\mathrm{e}}$ siècle», Cristina de la Puente (ed.), Identidades marginales, Madrid, CSIC, 2003a: 413-430.

Molénat, Jean-Pierre, «L'élite mudejare de Tolède aux XIVe et XVe siècle. Alfaquís, alcaldes et alcaldes de moros», Dominique Barthélemy y Jean Marie Martin (eds.), Liber Largitorius. Études d'Histoire Médiévale offertes à Pierre Toubert par ses élèves, Génova, Droz, 2003b: 563-577.

Ortega Álvarez, Javier, «El acceso de don Gutierre de Sotomayor al Maestrazgo de la Orden de Alcántara: orígenes y consecuencias», Espacio, Tiempo, Forma. Serie III, Historia Medieval, 24 (Madrid, 2011): 237-278. 
Ortega Álvarez, Javier, «La "Casa" de Don Gutierre de Sotomayor, Maestre de Alcántara: Una aproximación a la prosopografía de la Orden de Alcántara», Revista de Estudios Extremeños, LXVI/1 (Badajoz, 2010): 239-286.

Ortego Rico, Pablo, «Elites y clientelas mudéjares de Guadalajara durante el siglo XV», XI Simposio Internacional de Mudejarismo, Teruel, Instituto de Estudios Turolenses-Centro de Estudios Mudéjares 2009: 645-658.

Ortego Rico, Pablo, «Cristianos y mudéjares ante la conversión de 1502. Mercedes a moros. Mercedes de bienes de moros», Espacio, Tiempo y Forma. Serie III. Historia Medieval, 24 (Madrid, 2011): 279-318.

Ortego Rico, Pablo, «Mudéjares castellanos y fiscalidad real a fines del Medievo: élites, reparto, conflicto y fraude», Ángel Galán Sánchez y Pablo Ortego Rico (eds.), El precio de la diferencia en la Castilla Medieval y Moderna, Madrid, Sílex Ediciones, en prensa.

Sánchez Prieto, Ana Belén, La casa de Mendoza hasta el tercer Duque del Infantado (1350-1531): el ejercicio del alcance del poder señorial en la Castilla bajomedieval, Madrid, Palafox \& Pezuela, 2001.

Sánchez Rubio, María de los Ángeles, El concejo de Trujillo y su alfoz en el tránsito de la Edad Media a la Edad Moderna, Badajoz, Universidad de Extremadura, 1993.

Suárez Fernández, Luis, Documentos acerca de la expulsión de los judios, Valladolid, CSIC, 1964.

Torres Fontes, Juan, «El alcalde mayor de las aljamas de moros en Castilla», Anuario de Historia del Derecho Español, 32 (Madrid, 1962): 131-182.

Villalba Ruiz de Toledo, Francisco Javier, «Colección Diplomática del cardenal Mendoza (1454-1503)», Cuadernos de Historia Medieval. Secc. Colecciones Documentales, 1 (Madrid, 1999), 1-521.

Viñuales Ferreiro, Gonzalo, «El repartimiento del "servicio y medio servicio" de los mudéjares de Castilla en el último cuarto del siglo XV», Al-Qantara, 14/1 (Madrid, 2003): 179-202.

Viñuales Ferreiro, Gonzalo, «Aproximación al estudio de la comunidad mudéjar de Guadalajara en la Edad Media», 30 años de mudejarismo: memoria y futuro (1975-2005), Teruel, Instituto de Estudios Turolenses-Centro de Estudios Mudéjares, 2007: 501-512.

Viñuales Ferreiro, Gonzalo, «Aspectos de la convivencia entre moros y judíos en la ciudad de Guadalajara en la Edad Media», XI Simposio Internacional de Mudejarismo, Teruel, Instituto de Estudios Turolenses-Centro de Estudios Mudéjares 2009: 635-644.

Recibido: 21/10/2013

Aceptado: 08/09/2014 